but those in which the skin kept hot and dry after repeated attempts to act upon it, generally terminated fatally. The latter is the plan of treatment I have continued to adopt for some time past, but with success far, very far from what I could wish. A great deal, nay, all, has yet to be learned of this mysterious disease before we can expect to have anything like success in curing it.

The post-mortem appearances, I regret to say, do not throw much light on the pathology of the disease. One might be led to look to the stomach as the organ mostly implicated; but in some cases there was not the slightest trace of disease here; in others there was complete disorganization of the mucous coat: these two extremes are very difficult to account for. Then, again, what changes in the system does black vomit indicate, for death generally followed jt? Nearly all were doomed after this symptom set in; they sank and died from hæmorrhage, for black vomit is nothing more or less than blood mixed with gastric juice. I have often seen the blood vomited quite pure, and likewise found it so in the stomach after death. The occasion of black vomit is, nature endeavoring to throw off from the system a poison, even at the expense of the powers of life; the vital powers being low, exudation goes on rapidly from the mucous membrane of the stomach and the bowels. The blood in all cases is found fluid, dark and highly carbonized, clearly showing that the poison falls heavily on the vital fuid. 'The liver is found firmer than natural; at the same time it is bloodless, and always of a light lemon color; the latter peculiar to the disease. The intestines are generally healthy, but full of the peculiar thick, tarry secretion. The vessels of the brain in some cases were congested, and effused nto the ventricles; in others these were healthy. No traces of the disease were detected in other parts of the system.

\title{
SINGULAR CASE OF DELIRIUM RELIEVED BY CHLOROFORM.
}

BY C. J. POPE, M.D., OF ALABAMA.

What I propose on the present occasion is to direct attention to the internal administration of chloroform in all cases of exaltation of vital action, dependent on nervous excitability.

The effects of this remedy in the case recorded below, although a solitary one, were so marked and salutary, that my mind was brought to the conclusion that in all similar cases its effects would be no less striking.

About the first of February I was called in haste to see a lad, of about 14 years of age, who, immediately on rising from his bed, at a very early hour in the morning, and before it was entirely light, went under the dwelling of his father for the purpose of getting the eggs out of a hen's nest, in a hole of considerable depth, scratched out by the dogs. On getting into the hole, which was in depth about two thirds his entire length, the hen, which he had not supposed to be on the nest at that early hour, flew into his face, and this circumstance, together with that of his hold breaking, on attempting quickly to recover himself, so frightened him that spasms of the most violent character were the result. I saw him in 
half an hour after this happened, and at once opened the temporal artery, and bled him two ounces, which, however, had no effect in controlling the spasms. In a few minutes after the blood was stopped, I gave him an injection of tinct. lobelia. In five minutes the violence of the spasms seemed to be slightly controlled, but returned again in ten minutes more. The lobelia was again administered with the same partial ' effect, which lasted about the same length of time. Foiled in all my efforts thus far to arrest the spasms even temporarily, I had recourse to many other antispasmodics, but to no effect. The spasms continued for thirty-six hours, at the end of which time they passed off, and left him in a most singular state of delirium, which lasted seven or eight days without a lucid interval.

Large doses of opium and camphor would partially quiet him for an hour or two, but the delirium invariably returned. Finally, having given up all hope of his recovery, I resolved upon the following prescription: Aquæ camphoræ, $\xi \mathrm{ij}$; tinct. valerian, $\xi \mathrm{ij}$.; chloroform, $\xi \mathrm{j}$. Mixed. Of this I gave him a tablespoonful, and in five minutes I perceived indications of quietude. I waited one hour and a half, at the expiration of which time I found symptoms of returning delirium. I then gave him a second and rather larger dose. In ten minutes he was quiet, in twenty-five minutes I had the satisfaction of seeing him in a fine sleep, which lasted all night (it being then about 10 o'clock), and out of which he awoke on the following morning, entirely restored in mind, without any consciousness of what had transpired during the eight days of his illness.

His convalescence was prompt, and his recovery perfect.-Philadelphia Medical Examiner.

OXALATE OF LIME, AND ITS RELATIONS TO CERTAIN FORMS OF NEURALGIA.

BY H. A. JOHNSON, M.D.

$\mathbf{W}_{\mathbf{E}}$ are indebted for what we know of this deposit mostly to Dr. Golding Bird. From his observations he was led to the conclusion, that oxalate of lime occurs in more than one third of the cases in connection with an excess of uric acid or urate of ammonia ; that in all cases, there is an excess of urea, and that it is frequently accompanied by an excess of the phosphates. He also thinks it probable, that the uric and oxalic diatheses are both produced by the same morbid influences.

Uric acid, as existing in normal urine, is, without doubt, derived from the nitrogenized tissues of the body; but when found in excess, it may usually be traced either to ingesta, which the juices of the stomach have not power to dissolve, or to a too rapid destruction of tissues under the influence of heat, \&c., as in fevers and inflammation; can oxalic acid be traced to a similar source ?

Dr. G. Bird has presented a very ingenious theory for the production of this acid from urea and uric acid, but there is generally an excess of one or both of these ingredients accompanying the oxalic deposits. Should we expect this to be the case, if the abnormal product was the 